\title{
Crystal Type Iof Azilsartan Polymorphs: Preparation and Analysis
}

\author{
Yuhua Ge*, Tingting Li, Jingjing Cheng \\ School of Chemistry and Chemical Engineering, Southeast University, Nanjing, China \\ Email: 101004698@seu.edu.cn
}

Received 8 July 2015; accepted 25 January 2016; published 28 January 2016

Copyright (C) 2016 by authors and Scientific Research Publishing Inc.

This work is licensed under the Creative Commons Attribution International License (CC BY).

http://creativecommons.org/licenses/by/4.0/

(c) (i) Open Access

\begin{abstract}
Azilsartan (2-ethoxy-1-([2'-(5-oxo-4,5-dihydro-1,2,4-oxadiazol-3-yl)biphenyl-4-yl]methyl)-1H-benzimidazole-7-carboxylic acid) is a new angiotensin II receptor antagonist used in the treatment of hypertension. This paper describes the preparation of type I crystal and its single crystal diffraction data, the comparison of the powder diffraction data for both type I and II crystals as well as their stability and solubility in methanol.
\end{abstract}

Keywords

Azilsartan, Single Crystal Diffraction, Powder Diffraction, Solubility, Stability

\section{Introduction}

The structure of Azilsartan (2-ethoxy-1-([2'-(5-oxo-4,5-dihydro-1,2,4-oxadiazol-3-yl)biphenyl-4-yl]methyl)-1Hbenzimidazole-7-carboxylicacid) is shown below. It is reported firstly by Takeda in its prodrug formazilsartanme-doxomil ((5-methyl-2-oxo-1,3-dioxol-4-yl)methyl ester). This drug is an angiotensin II receptor ant-agonist.<smiles>CCOc1nc2cccc(C(=O)O)c2n1Cc1ccc(-c2ccccc2-c2noc(=O)[nH]2)cc1</smiles>

How to cite this paper: Ge, Y.H., Li, T.T. and Cheng, J.J. (2016) Crystal Type lof Azilsartan Polymorphs: Preparation and Analysis. Journal of Crystallization Process and Technology, 6, 1-10. http://dx.doi.org/10.4236/jcpt.2016.61001 
Its mechanism is the selective block of the binding of angiotensin II with receptor $\mathrm{AT}_{1}$ and thus the resulting. It can be prescribed as a treatment for hypertension by itself or in com-bination with other anti-hypertension drugs, blood vessel constriction [1]. It does not function through the biosynthetic pathway of an-giotensin II, thus avoids affecting the concentration of bradykinin as ACE inhibitors. Azilsartan has no common side effects such as dry cough [2].

Different types of crystals from the same drug can have different solubility and absorbility in our body and thus impact on its clinical efficacy and safety. Therefore, crystal types may directly affect the quality and efficacy of drugs. The study of the polymorphiccrystal types of Azilsartan will facilitate the improvement of its stability during preparation and storage. The research will also help to improve the bioavailability and efficacy and to reduce toticity [3].

Azilsartan is a white powder. Four types of crystalline powder have been reported with respective melting points (mp) of 122 - 123 (type III), 163 - 164 (type II), 180 - 181 (type IV), and $198^{\circ} \mathrm{C}$ - $206^{\circ} \mathrm{C}$ (type I) [4]-[6]. The preparation of type II and III crystals has been reported [4] [6]. Type II crystal is obtained from DMF and acetone; whereas type III crystal is from DMF and isopropanol. The preparation of type IV crystal from THF has also been reported [5]. However, only powder diffraction data for these crystal types have been reported and no single crystal diffraction data are available. Furthermore, the stability and solubility of these crystal types have not been carefully investigated.

We have obtained type I crystal of Azilsartan from methanol. The crystals melt at $198^{\circ} \mathrm{C}-201^{\circ} \mathrm{C}$ and are not hydroscopic. The advantage of this method is the low toxicity of methanol solvent and thus the suitability for pharmaceutical application. We analyze the single crystal diffraction, measure the solubility of type I and II crystals in methanol with HPLC, determine their $\mathrm{G}_{\mathrm{T}}$ values under different temperatures, and compare their stability.

\section{Experimental}

\subsection{Reagents and Instruments}

All reagents were analytical pure grade and were used without further purification. Melting points were determined using microscopic melting point apparatus. Single crystal diffraction data were obtained with Enraf-Nonius CAD4 X-ray diffractometer. Powder diffraction data were obtained with Bruker D8-Discover X-ray diffractometer. DSC data were obtained with Mettler-Toledo differential scanning calorimeter (the rate of heating is $10^{\circ} \mathrm{C} / \mathrm{min}$ ).

\subsection{Preparation of Azilsartan Type I and II Crystals}

Type I crystal: Methanol (100 mL) was added to an Erlenmeyer flask containing Azilsartan (2 g) and the mixture was stirred for 30 minutes. Another $100 \mathrm{~mL}$ of methanol was added to obtain a clear solution. To another flask was added $30 \mathrm{~mL}$ of the above clear solution, added $0.1 \mathrm{~g}$ valine, $6 \mathrm{~mL}$ water, and $5 \mathrm{~mL}$ methanol. The mixture was stirred for 30 minutes to obtain a clear solution. After two weeks,colorless crystals $(0.13 \mathrm{~g}, \mathrm{mp}$ $198^{\circ} \mathrm{C}-201^{\circ} \mathrm{C}$ ) were obtained.

Type II crystal: Type II crystals were prepared as white powder (mp 164 - 166) according to reported.

\subsection{Structural Determination of Azilsartan Type I Crystals}

All data were obtained at $20^{\circ} \mathrm{C}$ under MoKa ray $(\lambda=0.71073 \AA)$ and $\omega$-scanning method. Structure was solved and refined with SHELXL-97. Single crystal diffraction data were summarized in Table 1.

\subsection{Determination of the Solubilities of Azilsartan Type I and II Crystals in Methanol}

Sample Preparation: The powdered crystals $(0.5 \mathrm{~g})$ were each added to a flask with $15 \mathrm{~mL}$ methanol. The mixture was heated to $55^{\circ} \mathrm{C}$ and the temperature was maintained for 1 hour. An aliquot $(10 \mu \mathrm{L})$ of the solution was taken and mixed with $10 \mathrm{~mL}$ of the HPLC eluent (discussed below). This solution was further diluted with the same eluent ( $1 \mathrm{~mL}$ solution with $3 \mathrm{~mL}$ eluent) and filtered. The original sample solution in methanol was cooled to $50^{\circ} \mathrm{C}, 45^{\circ} \mathrm{C}, 40^{\circ} \mathrm{C}, 35^{\circ} \mathrm{C}$ and $30^{\circ} \mathrm{C}$. Samples at each temperature were prepared in the same manner.

Measurement: Measurement was done at $253 \mathrm{~nm}$ using WUFENGLC100 HPLC with reverse phase C18 column, eluent acetonitrile: water: acetic acid (57:43:1 by volume), temperature $30^{\circ} \mathrm{C}$, flow rate $1.0 \mathrm{~mL} / \mathrm{min}$ [7]. 
Table 1. Single crystal diffraction data for Azilsartan type I crystal.

\begin{tabular}{|c|c|}
\hline Parameter & Crystal I \\
\hline Chemical formula & $\mathrm{C}_{25} \mathrm{H}_{20} \mathrm{~N}_{4} \mathrm{O}_{5}$ \\
\hline Formula weight & 456.45 \\
\hline Crystal system & Monoclinic \\
\hline Space group & $\mathrm{P} 2{ }_{1} / \mathrm{C}$ \\
\hline $\mathrm{a}\left(\mathrm{A}^{\circ}\right)$ & 9.6590 (19) \\
\hline $\mathrm{b}\left(\mathrm{A}^{\circ}\right)$ & $11.329(2)$ \\
\hline $\mathrm{c}\left(\mathrm{A}^{\circ}\right)$ & $20.046(4)$ \\
\hline$\alpha\left({ }^{\circ}\right)$ & 90 \\
\hline$\beta\left(^{\circ}\right)$ & $90.30(3)$ \\
\hline$\gamma\left({ }^{\circ}\right)$ & 90 \\
\hline$V\left(A^{\circ 3}\right)$ & 2193.54 \\
\hline Formula units (Z) & 4 \\
\hline$\mu\left(\right.$ Mo Ka) $\left(\mathrm{mm}^{-1}\right)$ & 0.099 \\
\hline $\mathrm{T}(\mathrm{K})$ & $293(2)$ \\
\hline Reflections & 4284 \\
\hline Parameters & 308 \\
\hline Completeness (\%) & 99.8 \\
\hline R-Factor(\%) & 6.48 \\
\hline $\mathrm{R}$ indexes $\left(\right.$ on $\mathrm{F}^{2}>2 \sigma\left(\mathrm{F}^{2}\right)$ ) & $\mathrm{R} 1=0.0648 ; \mathrm{wR}^{2}=0.1460$ \\
\hline R(all data) & $\mathrm{R} 1=0.1423 ; \mathrm{wR}^{2}=0.1817$ \\
\hline Goodness-of fit(S) & 1.005 \\
\hline$\theta$ min.; max & $2.03 ; 25.38$ \\
\hline$\Delta \rho$ min.; max. $\left(\mathrm{e}^{\circ-3}\right)$ & $-0.204 ; 0.179$ \\
\hline
\end{tabular}

\section{Results and Discussion}

\subsection{DSC Curve of Azilsartan Type I and II Crystals}

The differential scanning calorimetry (DSC) curve of Azilsartan type I crystal (Figure 1) shows an endothermic process around $195^{\circ} \mathrm{C}$. An exothermic process follows immediately accompanied by loss of mass due to decomposition (mp $198^{\circ} \mathrm{C}-201^{\circ} \mathrm{C}$ ). Figure 2 shows similar observation with type II crystal around $163^{\circ} \mathrm{C}$ (mp $164^{\circ} \mathrm{C}-166^{\circ} \mathrm{C}$ ). The endothermic peaks of both crystal types are quite small. The decomposition temperature of type I crystal is higher than that of type II, which means that crystal type I is more stable than type II, consistent with the solubility data as discussed later.

\subsection{Crystal Structure of Azilsartan Type I Crystal}

Figure 3 is ORTEP Drawing of Azilsartan Type I Crystal (prob = 50) and Figure 4 is Ball-and-Stick Illustration of the Structure of Azilsartan Type I Crystal. The values of selected bond length, bond angle, dihedral angle, and torsional angle in Azilsartan type I crystal are summarized in Table 2 and Table 3. In the oxadiazole moiety, the torsional angles for C1-N1-C2-N2 and N1-C1-O2-N2 are $-0.8(4)$ and $-1.5(4)^{\circ}$, respectively, indicating that the ring is almost planar. The torsional angle for N1-C2-C3-C4 is $68.9(5)^{\circ}$, suggesting that the oxadiazole ring and the benzene ring are not exactly perpendicular to each other. The two benzene rings are also not perpendicular to each other, with the torsional angle for C3-C8-C9-C10 being 118.3(4) ${ }^{\circ}$. The dihedral angles between ring I $[\mathrm{O}(2) \mathrm{N}(2) \mathrm{C}(2) \mathrm{N}(1) \mathrm{C}(1)]$ and ring III $[\mathrm{C}(3) \mathrm{C}(4) \mathrm{C}(5) \mathrm{C}(6) \mathrm{C}(7) \mathrm{C}(8)]$ and between ring III and ring IV [C(9)C(10)C(11)C(12)C(13)C(14)] are 71.9(2) and 60.04(19) ${ }^{\circ}$, respectively, indicating a lack of coplanarity for these rings. On the other hand, ring II [N(3)C(16)N(4)C(17)C(22)] and ring V [C(17)C(18)C(19)C(20)C(21)C(22)] are almost coplanar, with a dihedral angle of $2.33(19)^{\circ}$. The carboxylic acid group on $\mathrm{C} 21$ has a torsional angle of $37.4(6)^{\circ}$ (C22-C21-C23-O3). 


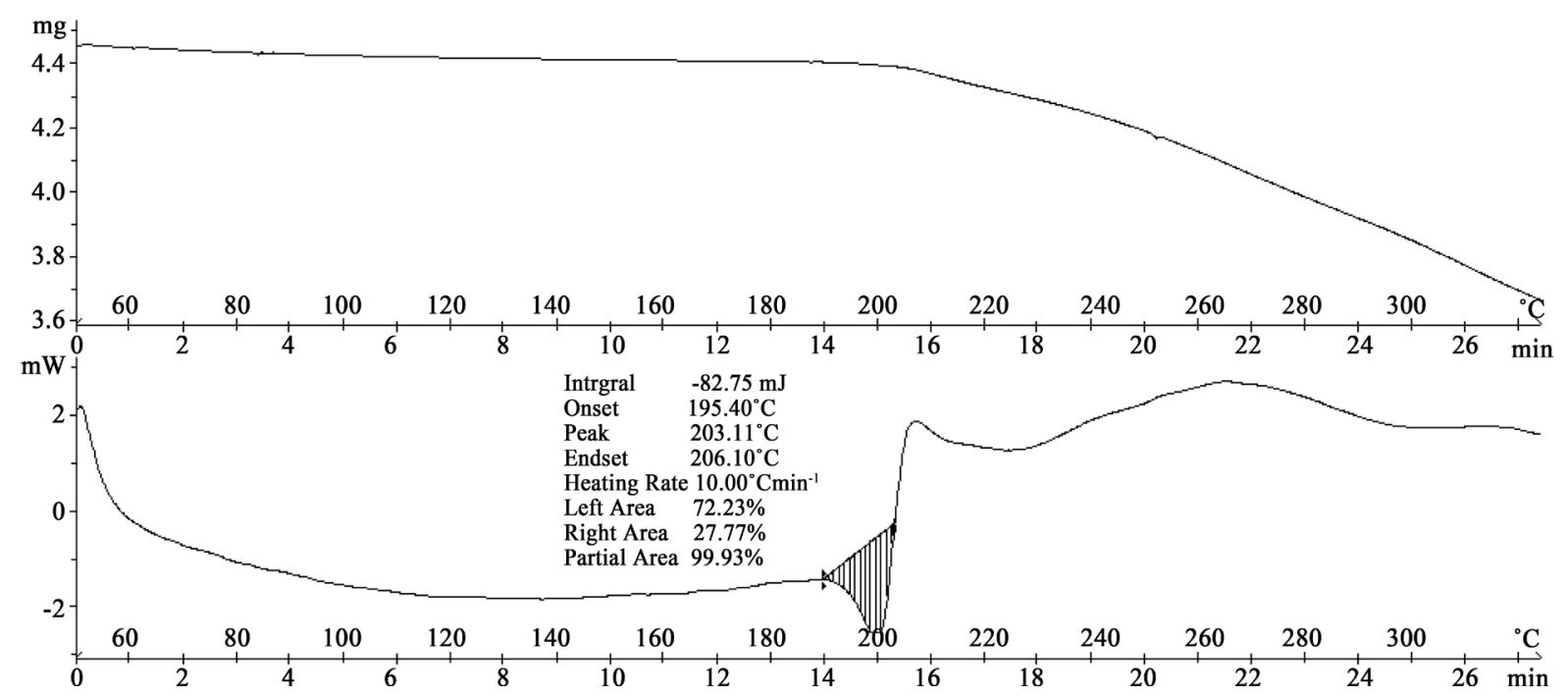

Figure 1. DSC Curve of Azilsartan type I crystal. (The rate of heating is $10^{\circ} \mathrm{C} / \mathrm{min}$ ).

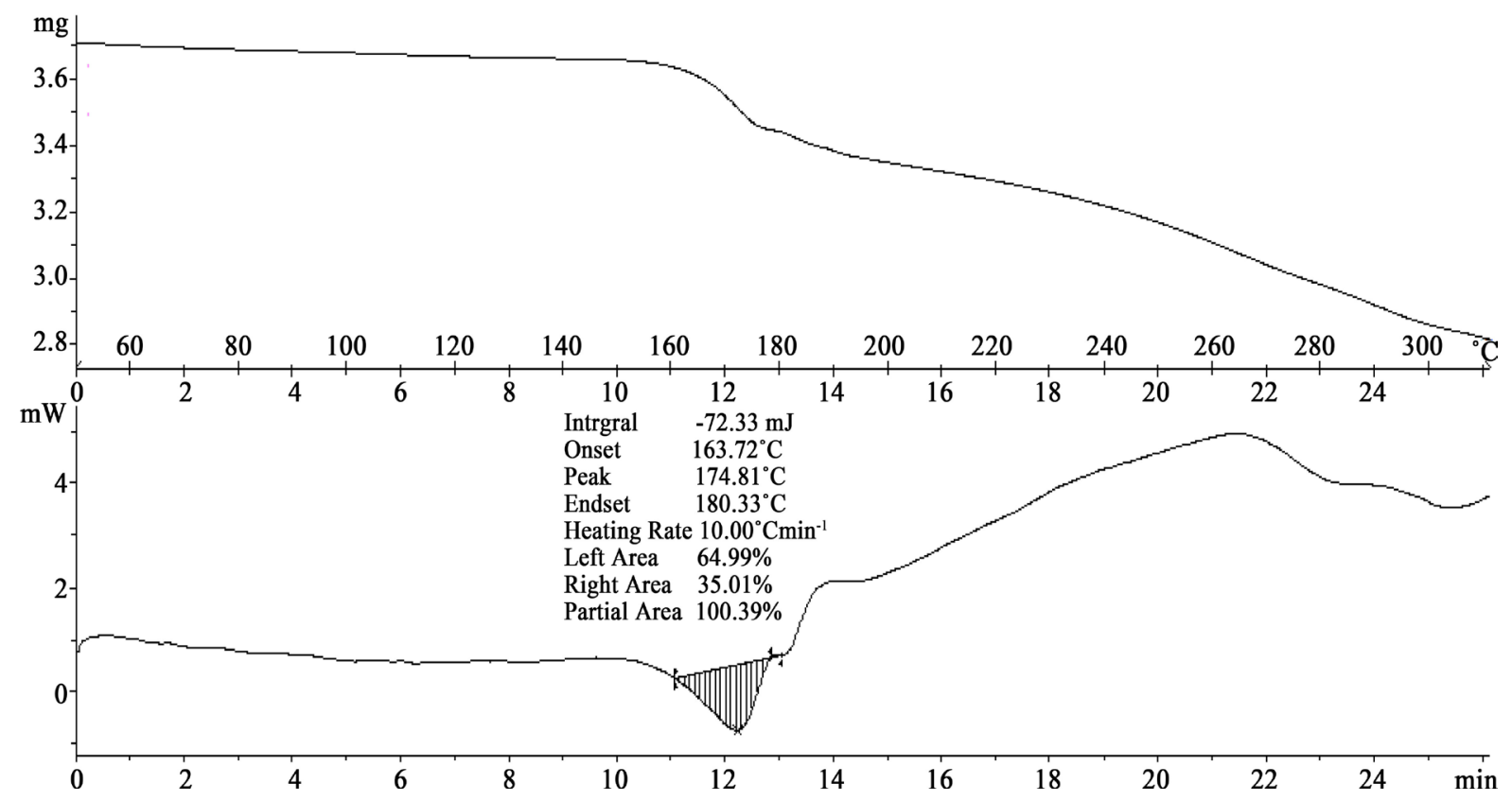

Figure 2. DSC Curve of Azilsartan type II crystal. (The rate of heating is $10^{\circ} \mathrm{C} / \mathrm{min}$ ).

Table 2. Selected bond length, bond angle, and dihedral angle values in Azilsartan type I crystal.

\begin{tabular}{cccc}
\hline Bond Length $(\AA)$ & & \\
\hline N1-C1 & $1.359(5)$ & N1-C2 & $1.369(4)$ \\
O1-C1 & $1.203(4)$ & C1-O2 & $1.355(4)$ \\
O2-N2 & $1.446(4)$ & N2-C2 & $1.288(4)$ \\
O3-C23 & $1.222(4)$ & O4-C23 & $1.308(4)$ \\
N3-C16 & $1.370(4)$ & N3-C22 & $1.387(4)$ \\
N3-C15 & $1.463(4)$ & N4-C16 & $1.299(4)$ \\
N4-C17 & $1.400(4)$ & O5-C16 & $1.332(4)$ \\
O5-C24 & $1.437(4)$ & & \\
\hline
\end{tabular}




\section{Continued}

\begin{tabular}{|c|c|c|c|c|c|c|}
\hline \multicolumn{7}{|l|}{ Bond Angle $\left({ }^{\circ}\right)$} \\
\hline C1-N1-C2 & \multicolumn{2}{|c|}{$108.5(3)$} & \multicolumn{2}{|c|}{ O1-C1-O2 } & \multicolumn{2}{|c|}{$123.8(4)$} \\
\hline O1-C1-N1 & \multicolumn{2}{|c|}{$130.7(4)$} & \multicolumn{2}{|c|}{ O2-C1-N1 } & \multicolumn{2}{|c|}{$105.4(3)$} \\
\hline C1-O2-N2 & \multicolumn{2}{|c|}{$109.8(3)$} & \multicolumn{2}{|c|}{ C2-N2-O2 } & \multicolumn{2}{|c|}{$103.8(3)$} \\
\hline N2-C2-N1 & \multicolumn{2}{|c|}{$112.4(3)$} & \multicolumn{2}{|c|}{ N2-C2-C3 } & \multicolumn{2}{|c|}{$124.2(3)$} \\
\hline N1-C2-C3 & \multicolumn{2}{|c|}{$123.4(3)$} & \multicolumn{2}{|c|}{ C16-N3-C22 } & \multicolumn{2}{|c|}{$105.5(3)$} \\
\hline C16-N3-C15 & \multicolumn{2}{|c|}{$123.5(3)$} & \multicolumn{2}{|c|}{ C22-N3-C15 } & \multicolumn{2}{|c|}{$131.1(3)$} \\
\hline C16-N4-C17 & \multicolumn{2}{|c|}{$103.0(3)$} & \multicolumn{2}{|c|}{ N3-C15-C12 } & \multicolumn{2}{|c|}{$114.0(3)$} \\
\hline C16-O5-C24 & \multicolumn{2}{|c|}{$118.2(3)$} & \multicolumn{2}{|c|}{ N4-C16-N3 } & \multicolumn{2}{|c|}{115.9 (3) } \\
\hline N4-C16-O5 & \multicolumn{2}{|c|}{$128.3(3)$} & \multicolumn{2}{|c|}{ C18-C17-N4 } & \multicolumn{2}{|c|}{$128.1(3)$} \\
\hline O5-C16-N3 & \multicolumn{2}{|c|}{115.9 (3) } & \multicolumn{2}{|c|}{ N3-C22-C21 } & \multicolumn{2}{|c|}{$134.0(3)$} \\
\hline N4-C17-C22 & \multicolumn{2}{|c|}{110.9 (3) } & \multicolumn{2}{|c|}{ O3-C23-O4 } & \multicolumn{2}{|c|}{$122.7(4)$} \\
\hline N3-C22-C17 & \multicolumn{2}{|c|}{$104.8(3)$} & & C23-C21 & & $3(3)$ \\
\hline O3-C23-C21 & 123. & & & C24-C25 & & $.9(3)$ \\
\hline Dihe & & & & & & \\
\hline & & I & II & III & IV & V \\
\hline I O $(2) \mathrm{N}$ & & & & & & \\
\hline II N(3)C( & & $35.9(2)$ & & & & \\
\hline III C(3)C( & & $71.9(2)$ & $47.1(2)$ & & & \\
\hline IV C(9)C(10) & & $76.7(2)$ & $68.2(2)$ & $60.04(19)$ & & \\
\hline V C(17)C(18) & & 38.05 (19) & $2.33(19)$ & $46.78(18)$ & $65.93(18)$ & \\
\hline VI N(3)C(16)N(4)C(1 & $\mathrm{C}(22)$ & $37.11(17)$ & $1.28(17)$ & $46.87(16)$ & $66.94(16)$ & 1.05 (15) \\
\hline
\end{tabular}

Table 3. Torsional angle values in Azilsartan type I crystal.

\begin{tabular}{cccc}
\hline Torsional Angle $\left(^{\circ}\right)$ & & & \\
\hline N1-C2-C3-C4 & $68.9(5)$ & N2-C2-C3-C8 & $74.7(5)$ \\
C1-N1-C2-N2 & $-0.8(4)$ & O1-C1-O2-N2 & $-179.9(4)$ \\
C3-C8-C9-C10 & $118.3(4)$ & C16-N3-C15-C12 & $62.5(5)$ \\
C13-C12-C15-N3 & $14.1(5)$ & C22-N3-C15-C12 & $-178.5(3)$ \\
C23-C21-C22-N3 & $7.5(7)$ & N4-C17-C22-C21 & $177.8(4)$ \\
N4-C17-C22-N3 & $-1.3(4)$ & N4-C17-C18-C19 & $3.2(6)$ \\
C22-C21-C23-O3 & $37.4(6)$ & C24-O5-C16-N4 & $170.4(4)$ \\
C22-N3-C16-N4 & $0.2(4)$ & C16-O5-C24-C25 & \\
N1-C1-O2-N2 & $-1.5(4)$ & & \\
\hline
\end{tabular}

In the crystal, the main molecular interaction is hydrogen bonding interaction. As seen in Table 4, the distance between $\mathrm{H} 1 \ldots \mathrm{N} 4$ is longer than that of $\mathrm{H} 4 \ldots \mathrm{O} 3$, indicating a stronger hydrogen bond in $\mathrm{O} 4-\mathrm{H} 4 \ldots \mathrm{O} 3$. The bond $\mathrm{O} 4-\mathrm{H} 4 \ldots \mathrm{O} 3$ is almost linear, ideal for hydrogen bond formation [8] the strength of this hydrogen bond is also reflected in the short O3... O4 distance (the reported range is 3.2 - $4.0 \AA$ ) [9]. The C18-H18... O1 intermolecular hydrogen bond is weaker, with the hydrogen much closer to the donor atom (C18).

The crystal lattice-packing graph along axis b and c are shown in Figure 5 and Figure 6, respectively, whereas the space-filling model is depicted in Figure 7 . There are $\pi$ - $\pi$ stacking interactions between the imidazole rings of neighboring cells. The distance between the centers of the rings is $5.557 \AA$ and the vertical distance between the two rings is $3.507 \AA$.

\subsection{XRD Data for Azilsartan Type I and II Crystals}

The simulated and observed powder diffraction graphs of Azilsartan type I crystal were shown in Figure 8 and Figure 9 , respectively. Peaks were observed at $2 \theta$ values of $9.01^{\circ}, 12.91^{\circ}, 15.52^{\circ}, 18.38^{\circ}, 19.43^{\circ}, 21.50^{\circ}, 23.58^{\circ}$, and $26.72^{\circ}$, in good agreement with the simulated values. These values are also consistent with the reported val- 
Table 4. Hydrogen-bonding parameters in Azilsartan type I crystal.

\begin{tabular}{|c|c|c|c|c|}
\hline D-H...A & D-H...( $(\AA)$ & H...A $(\AA)$ & D...A $(\AA)$ & D-H...A $\left({ }^{\circ}\right)$ \\
\hline N1-H1...N4 & 0.86 & 2.068 & $2.915(4)$ & 168.04 \\
\hline O4-H4...O3 & 0.819 & 1.862 & $2.681(4)$ & 179.73 \\
\hline C18-H18...O1 & 0.93 & 2.57 & $3.458(5)$ & 160 \\
\hline
\end{tabular}

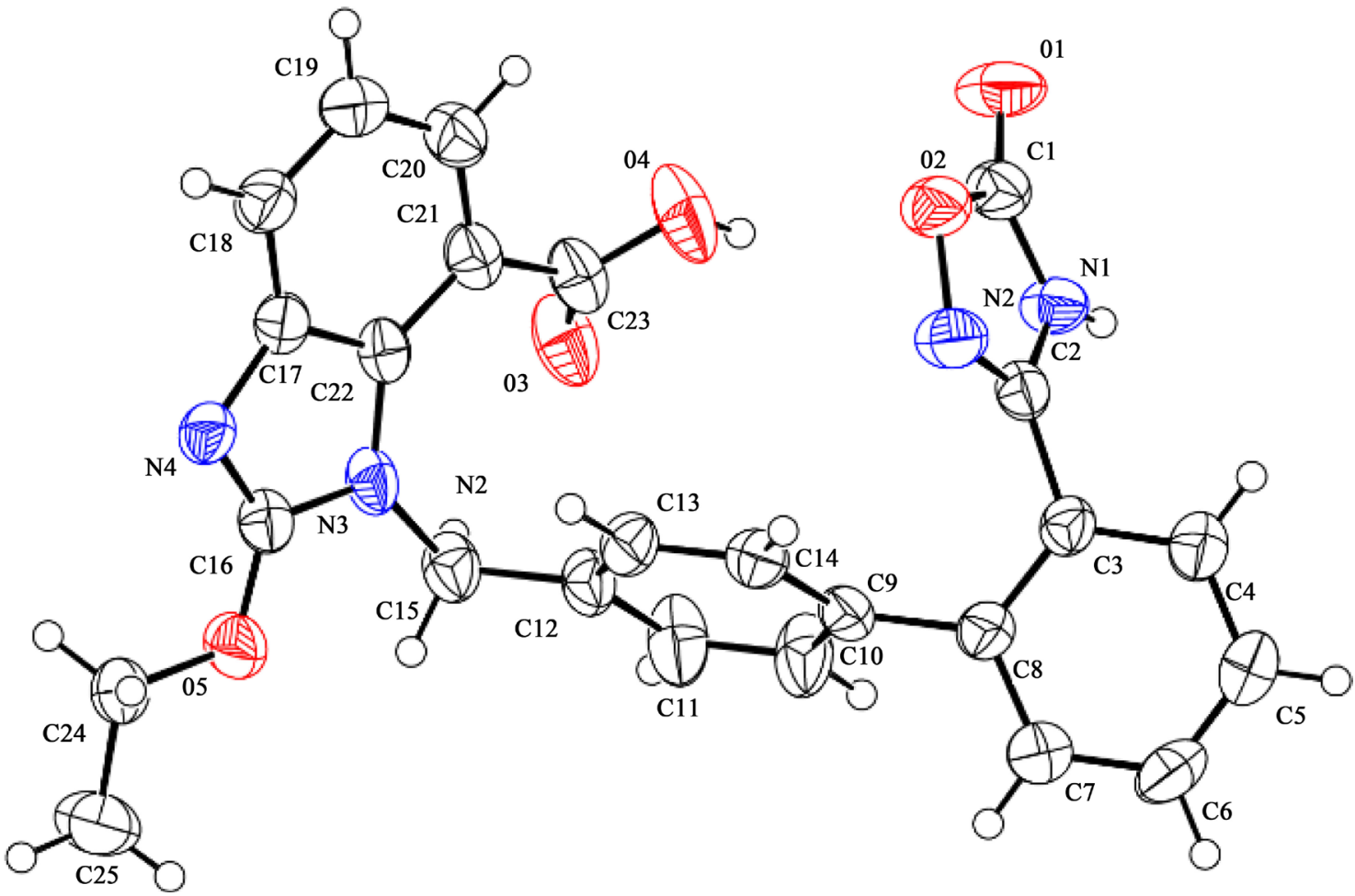

Figure 3. ORTEP drawing of Azilsartan type I crystal (prob = 50).

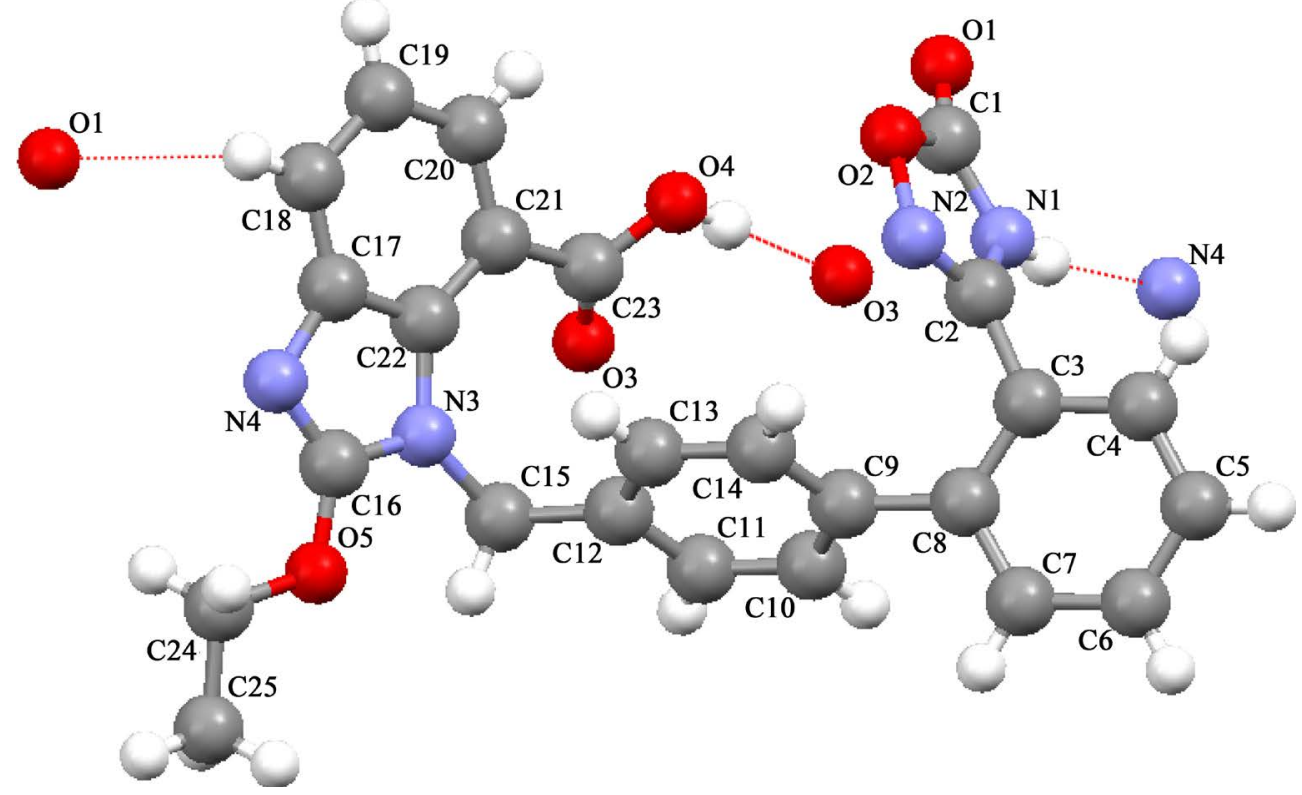

Figure 4. Ball-and-stick illustration of the structure of Azilsartan type I crystal (dashed line indicating hydrogen bonds). 


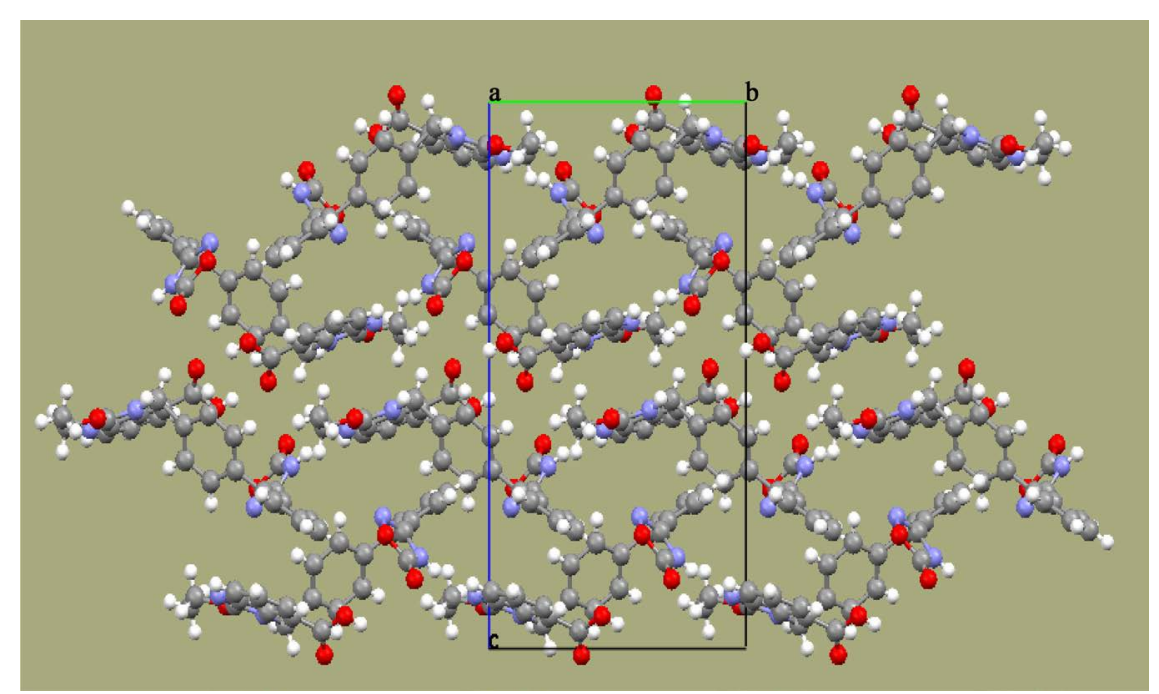

Figure 5. Crystal lattice-packing graph along axis a.

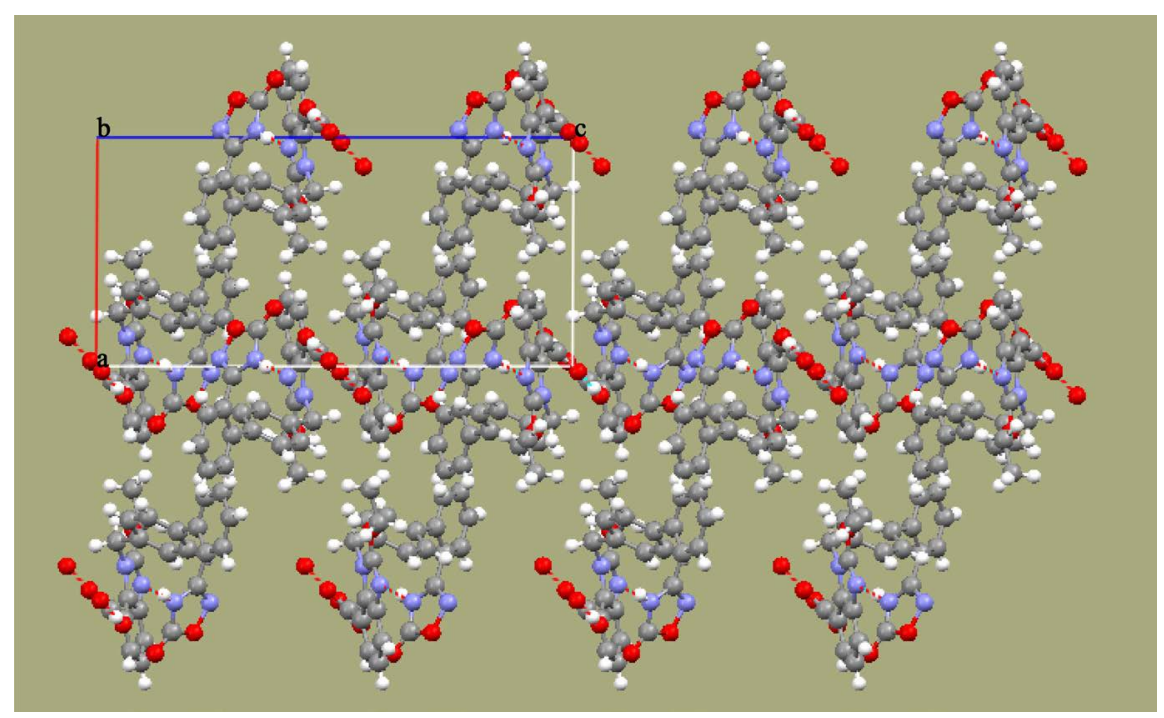

Figure 6. Crystal lattice-packing graph along axis b.

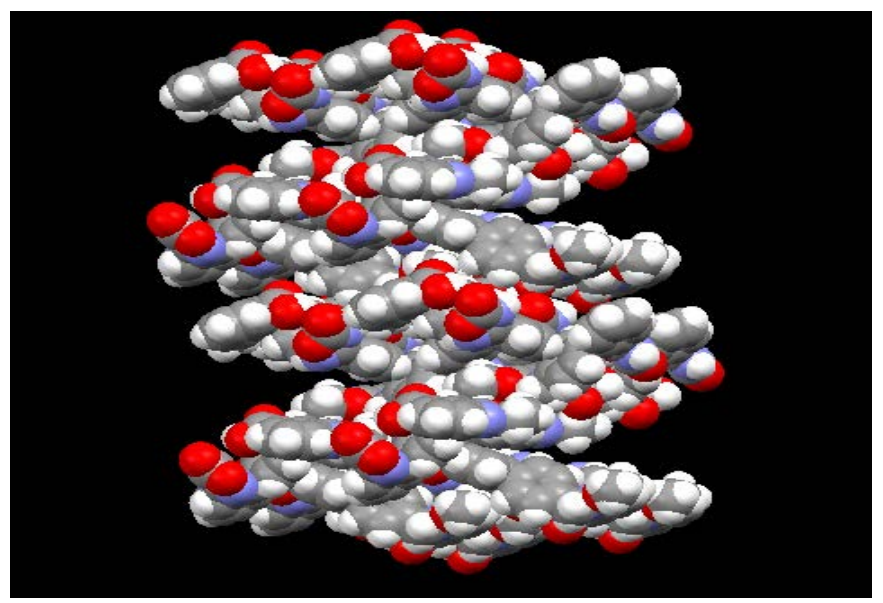

Figure 7. Space-filling model of crystal I for Azilsartan. 


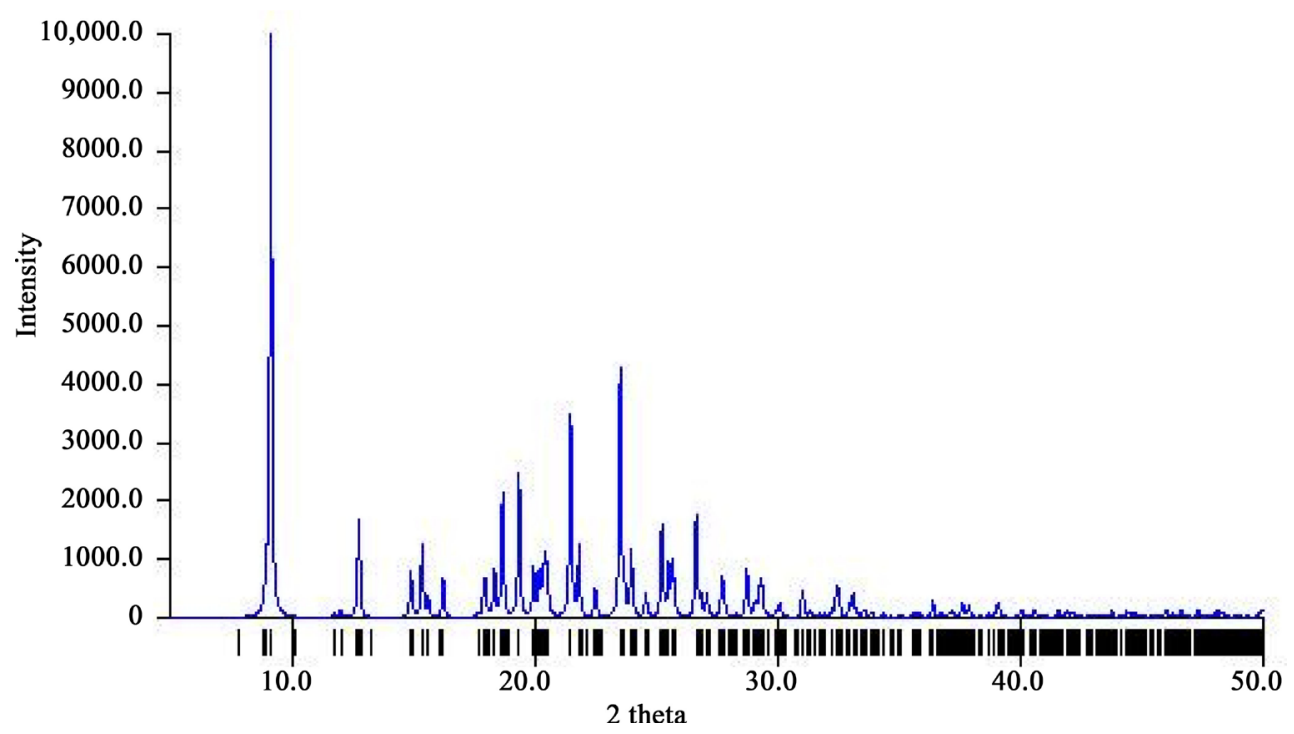

Figure 8. Simulated powder diffraction graph of Azilsartan type I crystal.

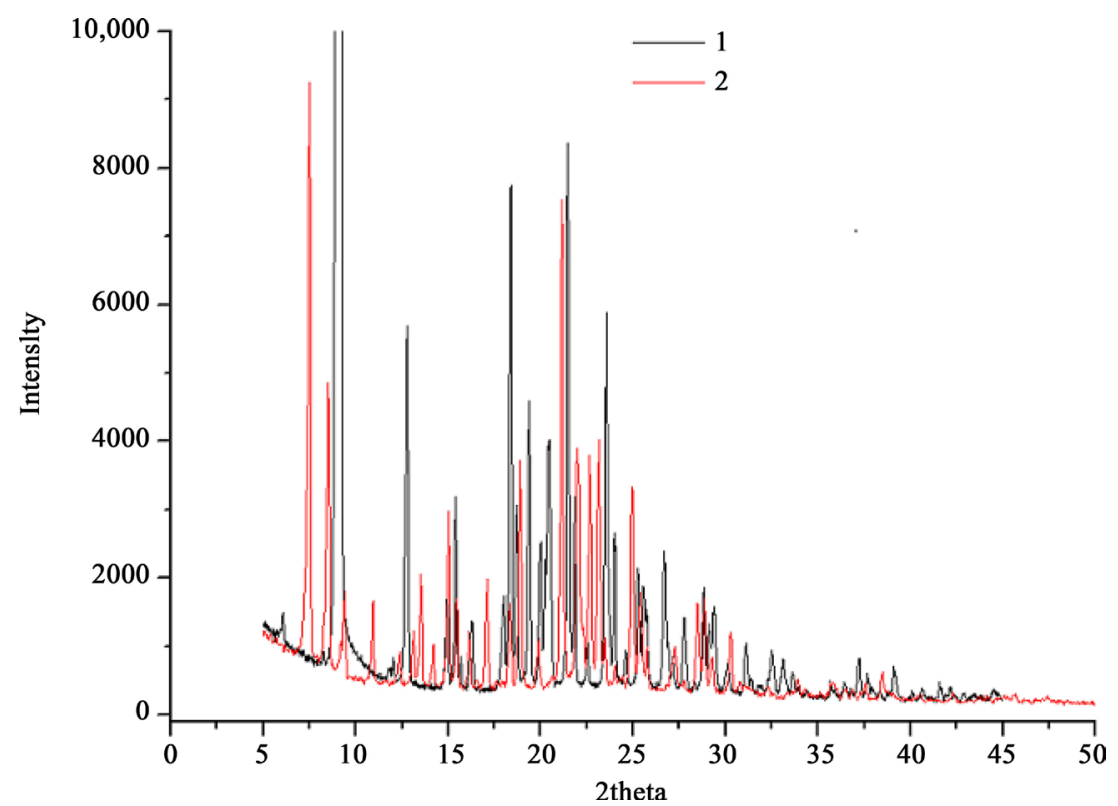

Figure 9. Overlaid powder diffraction graph of Azilsartan crystals (1 is type I, 2 is type II).

ues for a powder obtained from methanol and water [6]. The powder diffraction graphs of the two crystals were overlaid in Figure 9 for comparison. The different DSC curves and powder diffraction data have demonstrated that type I and II crystals are different.

\subsection{Solubility in Methanol and Stability of Azilsartan Type I and II Crystals}

The thermostability of different crystals can be inferred from their solubility in the same solvent. The solubility data in methanol are shown in Figure 10 (a). In the temperature range of $30^{\circ} \mathrm{C}-55^{\circ} \mathrm{C}$, the solubility of type I crystal is always lower than that of type II crystal and phase transformation is not observed. The solubility data and the melting point data both suggest that type I crystal is more stable than type II.

The enthalpy of solution $\left(\Delta \mathrm{H}_{\mathrm{s}}\right)$ can be calculated from the equation $\mathrm{InC}_{\mathrm{S}}=-\Delta \mathrm{H}_{\mathrm{S}} / \mathrm{R} *(1000 / \mathrm{T})+\beta$ by plotting the logithium of molar concentration against 1000/T as shown in Figure 10(b) [10]. The $\Delta \mathrm{H}_{\mathrm{s}}$ values for type I and II crystals are calculated to be 25.87 and $23.63 \mathrm{~J} / \mathrm{mol}$, respectively. 


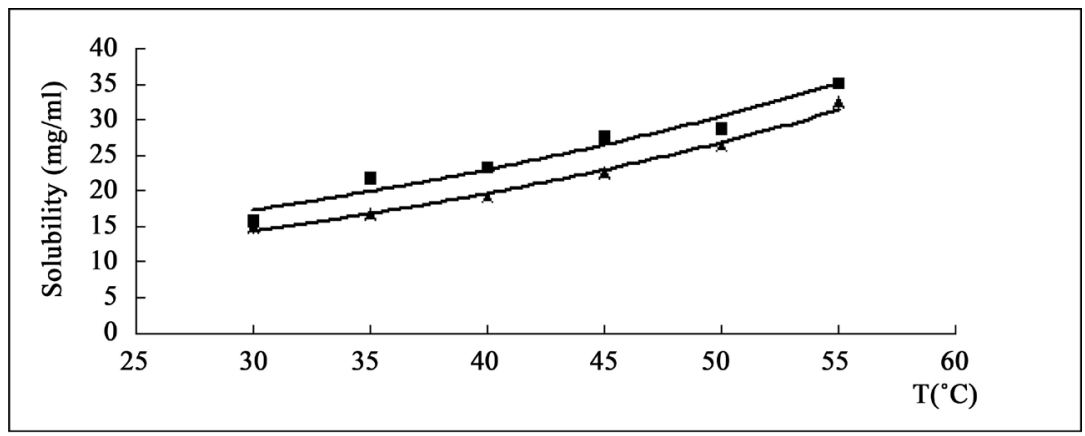

(a)

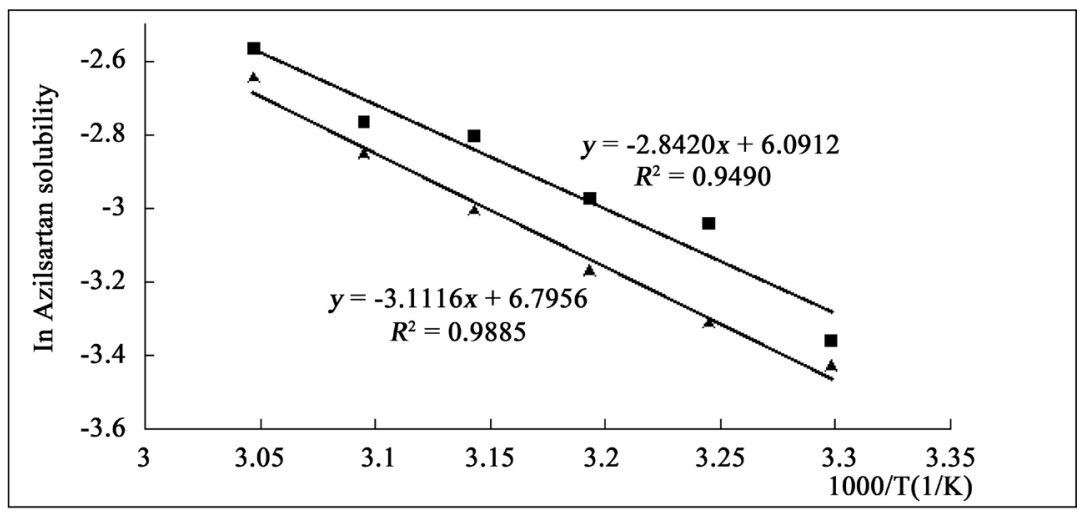

(b)

Figure 10. Solubility of the Azilsartan crystals in methanol (Triangle represents type I and square represents type II).

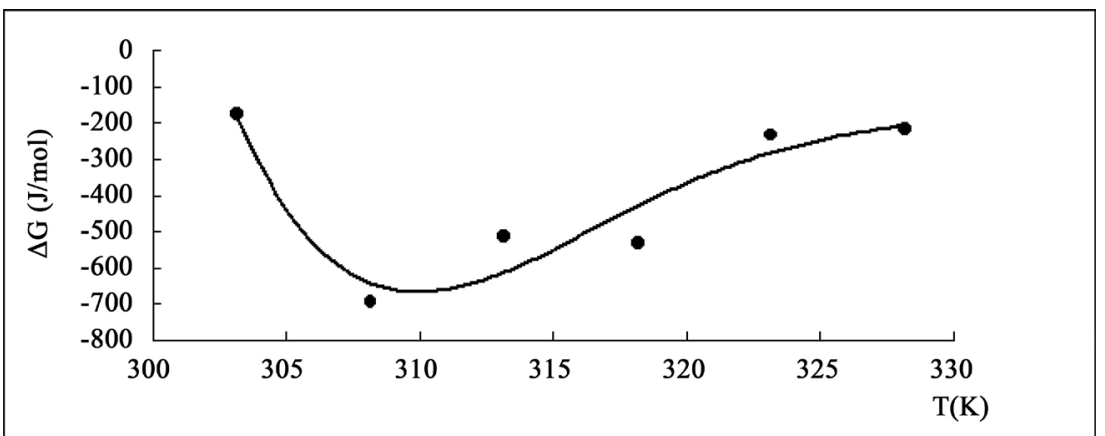

Figure 11. $\Delta \mathrm{G}_{\mathrm{T}}$ values of Azilsartan crystals at different temperatures.

The difference in Gibbs free energy of the two crystal types, $\Delta \mathrm{G}_{\mathrm{T}}$, has been calculated using the reported method [10]. The value $\Delta \mathrm{G}_{\mathrm{T}}$ initially decreases and then increases with rising temperature but stays negative (Figure 11).

\section{Conclusion}

Our results suggest that Azilsartan type I crystal is a single crystal. Single crystal structure indicates that cell lattice in type I crystal is formed from hydrogen bonding and $\pi-\pi$ interactions. Type I crystal has higher melting point than type II crystal. It is not hydroscopic and less soluble in methanol. Phase transformation is not observed in the experimental temperature range. Overall, type I crystal is more stable.

\section{Supporting Information}

CIF files of crystals 1 were deposited with the CCDC, CCDC No. 1029310 


\section{References}

[1] Singh, P., Fung, W.F. and Song, J.C. (2010) Focus on... Azilsartan: A Next-Generation Angiotensin II Receptor Blocker for the Treatment of Hypertension. Formulary, 45, 342-349.

[2] Lam, S. (2011) Azilsartan: A Newly Approved Angiotensin II Receptor Blocker. Cardiology in Review, 19, $300-304$. http://dx.doi.org/10.1097/crd.0b013e31822e9ba3

[3] Qiang, G., Lu, Y. and Du, G. (2009) The Present Situation and Development Direction of the Research for Polymorphic Drugs in China. Chinese Journal of New Drugs, 18, 1196-1200.

[4] Xu, Y., Zhou, H., Liu, W. and He, G. (2013) Azilsartan Polymorph and Preparation Method Thereof. Chinese Patent CN103319473A.

[5] Wang, X., Shui, Q., Tang, C., Liu, S., Ouyang, Q. and Shi, H. Azilsartan Crystal Form and Its Preparation and Application of the Same. Chinese Patent CN103880829A.

[6] Chen, Q., Zhu, Y., Zhang, L. and Ding, L. (2012) Polycrystalline Substance of Azilsartan and Preparation Method Thereof. Chinese Patent CN102766139B.

[7] Wu, B., Cui, H., Wang, J.and Wang, D. (2013) Hplc Analysis Method of Azilsartan. Chinese Patent CN103743826A.

[8] Chen, X. and Cai, J. (2007) Single Crystal Structural Analysis: Principles and Practice. Science Press, Beijing, 127128.

[9] Steed, J.W. and Atwood, J.L. (2009) Supramolecular Chemistry. 2nd Edition, Wliley, Chichester. http://dx.doi.org/10.1002/9780470740880

[10] Pranzo, M.B., Cruickshank, D., Coruzzi, M., Caira, M. R. and Bettini, R. (2010) Enantiotropically Related Albendazole Polymorphs. Journal of Pharmaceutical Sciences, 99, 3731-3742 http://dx.doi.org/10.1002/jps.22072 